6 Dyck P J. Hypoxic neuropathy: Does hypoxia play a role in diabetic neuropathy ?-The 1988 Robert Wartenburg lecture. Neurology 1989; 39: 111-8.

7 Evans D J, Cashman S J, Walport M. Progressive systemic sclerosis: autoimmune arteriopathy. Lancet 1987; i: 480-2.

8 McLeod J G, Tuck R R. Disorders of the autonomic nervous system: Part I. Pathophysiology and clinical features. Ann Neurol 1987; 21: 419-30.

9 Gledhill R F, Dessein P H M C. Autonomic neuropathy in systemic lupus erythematosus. J Neurol Neurosurg Psychiatry 1988; 51: $1238-40$.

\section{Does joint cartilage require energy?}

SIR, Geborek et al showed that induced increase of synovial fluid pressure decreases synovial blood flow, ${ }^{1}$ which, as expected, ${ }^{2}$ decreases synovial fluid oxygen tension. ${ }^{3}$ In five minutes synovial fluid pressure raised by flexion decreased synovial fluid oxygen tension in $3 / 10$ cases of knee trauma; these three synovial fluids contained few red cells, potential buffers against hypoxia. ${ }^{4}$ Even $\cdot$ at resting joint angles synovial fluid pressure correlated with synovial fluid hypoxia and, like synovial fluid volume, erythrocytes, and leucocytes also, with synovial fluid lactic acidosis (unpublished). Ischaemia cannot induce such changes unless oxygen and glucose are consumed.

We lack data on oxygen and glucose consumption in man, but Bywaters found that each mg of dry weight horse joint cartilage under aerobic conditions consumed $0.01 \mu \mathrm{l} / \mathrm{h}$ oxygen (his Table XIII) and produced $0.171 \mu \mathrm{l} / \mathrm{h}$ of lactate (Table VII), the rates in synovium being 0.8 and $1.7 \mu \mathrm{l} / \mathrm{h}$ respectively. $^{5}$ In rabbit leucocytes the rates were $4 \cdot 15$ (oxygen) and $22.5 \mu \mathrm{l} / \mathrm{h}$ (lactate). ${ }^{6}$ From the surface areas in one human $\mathrm{knee}^{7}$ the volume of the innermost vascular synovial intima was calculated to be $0.554 \mathrm{~cm}^{3}$ and that of cartilage $44 \mathrm{~cm}^{3}{ }^{8}$ We calculated that in $\mu \mathrm{mol} / \mathrm{h}(a)$ this cartilage consumed 3.924 oxygen and produced 67.1 lactate (water $80 \%$ ), (b) the synovial intima 5.93 oxygen and 12.6 lactate (water $70 \%$ ), and $(c) 10^{6}$ leucocytes (water $75 \%) 0.0419$ oxygen and 0.227 lactate. In each hour $(d) 10^{9}$ erythrocytes consume $0.027 \mu \mathrm{mol}$ oxygen and produce $0.384 \mu \mathrm{mol}$ lactate. ${ }^{9}$

In many cases of knee trauma (unpublished) synovial fluid leucocytes and red cells seemed to have consumed more oxygen and glucose than (required by?) the joint cartilage.

The regulation of glycolysis in cartilage differs from that in liver as entry of pyruvate into the citric acid cycle is possibly inhibited by acetyl-CoA derived from fat. ${ }^{10}$ In normal cartilage most of the energy may be produced by glycolysis, but if the oxygen consumed is used for oxidation of glucose $\mathrm{e}^{10-12}$ (lipids?) about a quarter of the energy may depend on oxygen. In acidotic joints proper energy supply might require more oxygen as glycolysis is depressed by high lactate concentrations.

Damage by reperfusion induced oxygen radicals has been stressed ${ }^{3}$ and considered. ${ }^{1}$ The synovial fluid oxygen tension dropped, however, at a rate $(61$ to $41 \mathrm{mmHg}$ in two minutes) ${ }^{3}$ that might soon have resulted in anoxia and which, at synovial fluid volumes $>10 \mathrm{ml}$, exceeded the calculated consumption by cartilage. We suggest that raised synovial fluid pressure and intra-articular cells deprive cartilage of energy. ${ }^{212}$ To avoid ischaemic metabolic joint damage one should refrain from measures? that disturb circulation in capillaries of cartilage in the synovium $^{8}$ (removed at early synovectomy) and aim ${ }^{\text {? }}$ instead to correct changes of physiological mechanismo that, by increasing synovial fluid volume, increase synovia $\overline{\underline{n}}$ fluid pressure, ${ }^{214}$ the simplest being rinsing of joints tof decrease the osmotic 'suck' of synovial fluid colloids.

Department of Pathology, JOHAN AHLQVIST⿱⺊口灬

Aurora Hospital, 00250 Helsinki

Department of Biochemistry, University of Helsinki, 00100 Helsinki

Orthopaedic Hospital, Invalid Foundation, 00200 Helsinki,

Finland

\section{References}

KAJ ÖSTERLUN岕

1 Geborek P, Forslind K, Wollheim F A. Direct assessment of synovial blood flow and its relation to induced hydrostatic pressure changes. Ann Rheum Dis 1989; 48: 281-6.

2 Ahlquist J. A physiological approach to the pathogenesis of rheumatoid and other high-protein arthropathies. Med Hypotheses 1988; 25: 77-88.

3 Blake D R, Unsworth J, Outhwaite J M, et al. Hypo® reperfusion injury in the inflamed human joint. Lancet 1989 289-93.

4 Harilainen A, Ahlqvist J, Lalla M, Myllynen P, Rokkanen Colloid osmotic and hydrostatic pressures and energy metabolism in high-protein joint swelling. A preliminary study of traumatic effusions of the knee. Clin Physiol 1989; 9: 221-31.응

5 Bywaters E G L. The metabolism of joint tissues. J Pathol 1937; 44: $247-68$.

6 Krebs H A, Johnson W A. Cell metabolism. In: Handovsky H, ed. Tabulae biologicae 29, Pars 3: Cellula. The Hague: Junk, 1948: 100-235.

7 Davies D V. Synovial membrane and synovial fluid of joints. Lancet 1946; ii: 815-9.

8 Ahlqvist $J$. On the structural and physiological basis of the influence of exercise, movement and immobilization in inflammatory joint diseases. Ann Chir Gynaecol 1985; 74 (suppl 198): $10-18$.

9 Waller H D. Biochemical determinants of red cell life span. Scand J Haematol 1965; 10: 34-52.

10 Dunham J, Dodds R A, Nahir A M, et al. Aerobic glycolysis of bone and cartilage: the possible involvement of fatty acid $\triangle$ oxidation. Cell Biochem Funct 1983; 1: 168-72.

11 Maroudas A. Metabolism of cartilaginous tissues: a quantitative approach. In: Maroudas A, Holborow E J, eds. Studies in joint disease 1. London: Pitman, 1981: 59-86.

12 Ahlqvist J. A hypothesis on the pathogenesis of rheumatoid and other non-specific synovitides. The possible intermediate role of $\mathbb{O}$ local hypoxia and metabolic alterations. Med Hypotheses 1984; 13: $257-302$.

13 Kusaka Y. ${ }^{31}$ P-NMR and HPLC studies on the energy metabolism of perfused chondrocytes. Nippon Seikeigekao Gakkai Zasshi 1985; 59: 1097-105.

14 Levick J R. Blood flow and mass transport in synovial joints. In: Renkin E M, Michel C C, eds. Handbook of physiology, cardiovascular system. Vol IV. Microcirculation, Part 2. T Bethesda, Maryland: American Physiological Society, 1984:O 917-47. 